\title{
Development and experimental validation of a computational model in order to simulate ice cube production in a thermoelectric ice maker.
}

\author{
A. Rodríguez, J.G. Vián, D. Astrain, \\ Dpto. Ingeniería Mecánica, Energética y de Materiales. Universidad Pública de \\ Navarra, Pamplona, Spain \\ Tel.+34 948169295, e-mail:vian@unavarra.es
}

\begin{abstract}
We have developed a computational model which allows the simulation of a thermoelectric device to make ice cubes in a vapor compression domestic fridge. This model solves both the thermoelectric and heat transfer equations, including the phase change equations in the ice cube production.

The inputs of the model are: the thermoelectric parameters as a function of the temperature; dimensions; material properties (thermal resistances and capacities) and the boundary conditions (room temperature and voltage supplied to the Peltier module). The outputs are the values of the temperature for all the elements of the thermoelectric ice-maker and the ice production.

In the experimental phase a prototype of a thermoelectric ice maker incorporated in a vapour compression domestic fridge was constructed in order to adjust and validate the computational model, and to optimize the experimental application. This ice-maker has two Peltier modules, some aluminum cylinders, called fingers, where the ice is made, and a component that acts as heat extender and dissipater which connects the hot side of Peltier module with the freezer compartment. The ice formation on the fingers is obtained by the cooling on the Peltier modules. When the ice cubes are formed, the voltage polarity of the thermoelectric modules is switched so the fingers warm up until the ice around the fingers melts. Then the ice cubes are dropped by gravity.

This paper studies the production of ice cubes using the computational model and the experiment results and analyzes the most important parameters for the optimisation of the ice-maker (voltage supplied to the Peltier module, thermal resistance of the hot side dissipater and initial water temperature).
\end{abstract}

Keywords: Ice cube, ice maker, thermoelectric, computational model.

\section{Nomenclature}

$\begin{array}{lll}A & \text { Area } & \left(\mathrm{m}^{2}\right) \\ C & \text { Thermal capacity } & \left(\mathrm{J} \mathrm{K}^{-1}\right) \\ \text { COP } & \text { Coefficient of performance } & \\ c_{p} & \text { Specific heat under constant pressure } & \left(\mathrm{J} \mathrm{kg}^{-1} \mathrm{~K}^{-1}\right) \\ e & \text { Thickness } & (\mathrm{m}) \\ h & \text { Convection coefficient } & \left(\mathrm{W} / \mathrm{m}^{2} \mathrm{~K}\right) \\ I & \text { Electric current } & (\mathrm{A}) \\ k & \text { Thermal conductivity } & \left.(\mathrm{W} \mathrm{m})^{-1} \mathrm{~K}^{-1}\right) \\ L & \text { Length } & (\mathrm{m}) \\ N & \text { Peltier module thermocouples number } & \end{array}$




$\begin{array}{lll}\dot{Q} & \text { Heat flux } & (\mathrm{W}) \\ \dot{Q}_{f} & \text { Heat flux absorbed by Peltier modules in the finger } & (\mathrm{W}) \\ \dot{*}^{*} & \text { Rate of internal generation of heat } & \left(\mathrm{W} \mathrm{m}^{-3}\right) \\ \mathrm{r} & \text { Radius } & (\mathrm{m}) \\ R & \text { Thermal resistance } & \left(\mathrm{K} \mathrm{W}^{-1}\right) \\ R_{c} & \text { Electric contact resistance } & (\mathrm{Ohm}) \\ R_{O} & \text { Electric Peltier module resistance } & (\mathrm{Ohm}) \\ \mathrm{t} & \text { Time } & (\mathrm{s}) \\ T & \text { Temperature } & (\mathrm{K}) \\ T^{\prime} & \text { Temperature in next step } & (\mathrm{K}) \\ V & \text { Voltage } & (\mathrm{V}) \\ \dot{W}_{p} & \text { Electric power of the Peltier device } & (\mathrm{W})\end{array}$

\section{Greek letters}

$\begin{array}{lll}\alpha & \text { Seebeck Coefficient } & (\mathrm{V} / \mathrm{K}) \\ \rho & \text { Density } & \left(\mathrm{kg} \mathrm{m}^{-3}\right)\end{array}$

\section{Superscripts, subscripts}

$\begin{array}{ll}\text { cp } & \text { Cold side of Peltier module } \\ \mathrm{c} & \text { Contact } \\ \mathrm{d} & \text { Dissipater } \\ \text { exp } & \text { Experimental } \\ \mathrm{f} & \text { fingers } \\ \mathrm{fr} & \text { Freezer } \\ \mathrm{fr} \text { term } & \text { Freezer thermostat } \\ \mathrm{hp} & \text { Hot side of Peltier module } \\ \mathrm{i} & \text { Node i } \\ \text { ice } & \text { Ice } \\ \text { ini w } & \text { Initial properties of the water } \\ \text { in } & \text { Insulation } \\ \mathrm{j} & \text { Node j } \\ \mathrm{J} & \text { Joule Effect } \\ \mathrm{m} & \text { Peltier module section } \\ \mathrm{pc} & \text { Phase change } \\ \mathrm{P} & \text { Peltier module } \\ \text { ref } & \text { Refrigerator } \\ \text { ref term } & \text { Refrigerator thermostat } \\ \mathrm{r} & \text { Room } \\ \text { sim } & \text { Simulated } \\ \text { solid } & \text { Solidification } \\ \mathrm{v} & \text { Vessel } \\ \mathrm{w} & \text { Water }\end{array}$




\section{Introduction}

The development of refrigeration equipment utilising thermoelectric technology can, in many cases, replace the current vapour compression refrigeration system. These thermoelectric systems have the advantage that they can produce both cold and heat by simply reversing the polarity of the Peltier module voltage. They are silent, does not vibrate and are low maintenance, because of their minimal use of moving parts and lack of cooling fluids and in many aspects are more environmentally friendly.

Nowadays this technology is used in a lot of applications, such as electric cabinet refrigeration, in portable refrigerators for medical, biological and leisure applications, and air-conditioned compartments, etc. Some of these applications are studied in references [1] and [2].

This technology has to compete with the traditional vapour compression systems. In order to improve the thermoelectric refrigerator COP it is necessary to address the followings factors: A good thermal contact in the assembly to avoid heat flux leaks; a low dissipater thermal resistance for an effective way to dissipate the heat flux; and the correct Peltier module voltage.

When developing applications based on thermoelectricity, one is presented with the problem of handling the combined equations of heat transfer and thermoelectric effects. There are several theoretical expressions to solve the COP of thermoelectric refrigerators, as indicated in reference [3], which assume a series of simplified hypotheses. In addition, the temperature of the Peltier module is required as a condition. This is an unknown parameter and it is necessary to determine its value experimentally. Although these temperatures were known, the results obtained from the use of this expression (the ideal thermocouple COP expression, as indicated in reference [3]) did 
not agree with the experimental results due to the use of the simplified hypotheses in the analytical solution.

The analogy existing between electric problems and thermal problems permits the study of the behaviour of a thermoelectric problem by resolving an equivalent electric network. This type of model has been employed in the study of different practical applications such as those shown in references [4] and [5].

This paper develops a computational method of calculation to obtain approximations of the experimental results and to simulate the function of a thermoelectric ice-maker situated in a domestic fridge, and to permit analysis and optimisation of production.

The model developed in this paper was in part used as the basis of a similar model created to simulate the behaviour of thermoelectric refrigerators for other applications [6] and [7].

\section{Objectives}

In order to carry out this research, we posed the following objectives:

- Development of a computational model to simulate the thermoelectric ice-maker (production of ice cubes, heat fluxes, temperatures, COP) and the behaviour of the refrigerator in which is placed.

- Experimental validation of the computational model using the experimental data obtained during the construction and testing of the thermoelectric ice-maker.

- Theoretical study and experimental validation of the ice cube production as a function of the Peltier module voltage for:

- A range of freezer compartment and chiller compartment temperatures. 
- Different heat dissipater configurations.

- Simulation of ice cube production as a function of initial supply water temperature.

\section{Description and operation of the thermoelectric ice maker.}

The principal of operation of the thermoelectric ice-maker can be seen in the diagram in Fig. 1. Its operation is based on the absorption of heat from the cold side of a Peltier module, which cools and freezes water in contact with it the cold side of Peltier module to a temperature below freezing.

The components on which the ice cubes are formed are here called "fingers". These consist of a flat aluminium plate, which has one side in contact with the cold side of Peltier module; the other side is connected to cylinders which are in contact with the water. The water used to produce the ice cubes is contained in a vessel. All these components are placed in the refrigerator compartment. When a heat absorption is initiated, the temperature of the fingers in contact with the water falls below freezing $\left(\mathrm{T}_{\text {solid }}=0{ }^{\circ} \mathrm{C}\right)$, and ice starts to form. The heat is rejected at the hot side of the Peltier module through the freezer compartment by means of a heat extender and dissipater; shown in Fig. 1.

Fig. 1: Diagram of the ice maker prototype.

The heat absorbed and dissipated is a function of the Peltier module voltage and therefore, there is an optimum voltage that minimises the time required for the formation of the ice cubes.

In order to detach the ice cubes, the polarity of the Peltier module is reversed. This heats the fingers which melt the contact points, releasing the ice cubes, which then fall 
away from the fingers under the effect of gravity. The time required to release the ice cubes is less than a minute.

The simulations carried out using the computational model permitted the design of the thermoelectric ice-maker and its behaviour to be optimized.

\section{Computational model}

The method most widely used, to solve the equations encountered in thermoelectric can be seen in reference [3]. This use a series of simplifying hypotheses: Constant thermoelectric properties, perfect electric bridges and ceramic layers with negligible thermal conductivity. These assumptions produce results which are far from the reality, by way of example, in the better operation conditions the experimental COP calculated for a thermoelectric refrigerator in the reference [7] is 0.616 and with the expression indicated in the reference [3] is 0.972 , this is an error of $58 \%$. In accordance with the proposed objectives, the research developed a computational model in order to obtain a more accurate approximation of the actual solution with a reduced computing time.

Our model uses the finite differences to solve a system of non-linear equations, which are the thermoelectric equations and the heat transfer equations, including those due to the phase change. Fig. 2 shows the discretization of the computational model in which the components of the ice-maker are divided into nodes. The model calculates the temperature in each of the nodes as a function of time. This permits the calculation of the transient states of the elements of the system to be carried out. In order to do this it is necessary to introduce the following inputs into the model.

The inputs needed for the model are:

- Geometry and material of the ice-maker.

- Peltier module specifications (material and dimensions). 
- Electric voltage of the Peltier module.

- Thermal resistance and capacities of the heat dissipater.

- Initial water temperature.

After the simulation the model supplies as outputs, the followings results:

- Temperatures of each of the elements of the system of the thermoelectric icemaker.

- Heat fluxes

- Electric power consumption of the Peltier module

- COP of the ice-maker

- Formation time of the ice cubes

Because all the temperatures and heat fluxes of the system can be determined knowing the specifications of the system and the voltage supplied to the Peltier modules. The model can be used as a design tool to build a thermoelectric ice-makers.

\subsection{Model hypotheses}

The hypotheses of the model are:

- The materials are considered isotropic.

- The Thomson effect is considered negligible, compared to the Peltier and Joule effects, as is indicated in reference [8].

- The model supposes the absence of magnetic fields, so the Hall, Nerst, Ettingshausen and Righi-Ludec effects are not taken into account, as is shown in the reference [9].

\subsection{Model equations}


The model solves the heat conduction equation in a transient state for the onedimensional case, as shown in expression (1).

$$
\rho c_{p} \frac{\delta T}{\delta t}=k\left(\frac{\delta^{2} T}{\delta x^{2}}\right)+q^{*}
$$

London et al [10] observed that the solidification of substances around tubes can be considered a one-dimensional problem if the cooling environment has a constant temperature or if the tubes are short, in the order of $(\mathrm{L} / \mathrm{D} \leq 100)$.

The heat conduction equation (1) multiplied by the volume, applied to the node $i$ as a function of the thermal resistances and capacities is:

$$
\frac{T_{i-1}{ }^{\prime}-T_{i}^{\prime}}{R_{i-1, i}}+\frac{T_{j}^{\prime}-T_{i}^{\prime}}{R_{i, j}}+\dot{Q}_{i}=\frac{C_{i}}{\delta t}\left(T_{i}{ }^{\prime}-T_{i}\right)
$$

The expressions of the thermal resistance between the nodes $i$ and $j$ and the thermal capacity of each node $\mathrm{i}$ are the inputs that our model requires. These values must be calculated with the maximum possible accuracy in order to ensure reliable results.

The discretization of the thermoelectric ice-maker uses the symbols of an electrical analogy, as is shown in Fig. 2. The model assigns different nodes for the ice and the water. The Peltier module is divided into nine nodes in order to determine with accuracy the temperature distribution in its interior.

The temperatures corresponding to the nodes indicated in Fig. 2 are:

- Node 1 and 28: Room temperature.

- Node 2: Refrigerator compartment temperature.

- Node 3: Vessel temperature.

- Node 4: Liquid water temperature.

- Node 5: Temperature of the ice formed on the fingers.

- Node 6: Finger temperature.

- Nodes from 7 to 24: Section of Peltier module temperature. 
- Node 25: Finger insulator temperature.

- Node 26: Dissipater temperature.

- Node 27: Freezer compartment temperature.

Fig. 2. Diagram of the electric and thermal analogy of the computational model

As an example we pose the expression (2) in relation to node 4, which is joined to nodes 5 and 3 , given as:

$$
\frac{T_{3}^{\prime}-T_{4}^{\prime}}{R_{v-w}}+\frac{T_{5}^{\prime}-T_{4}^{\prime}}{R_{w-i c e}}+\dot{Q}_{p c}=\frac{C_{4}}{\delta t}\left(T_{4}^{\prime}-T_{4}\right)
$$

Grouping terms in the expression (3) as a function of the temperatures in the following iteration (T current iteration, T' next iteration), we obtain the expression (4):

$$
-\frac{\delta t}{C_{4}} \frac{1}{R_{v-w}} T_{3}^{\prime}+\frac{\delta t}{C_{4}}\left(\frac{1}{R_{v-w}}+\frac{1}{R_{w-i c e}}+\frac{C_{4}}{\delta t}\right) T_{4}^{\prime}-\frac{\delta t}{C_{4}} \frac{1}{R_{w-i c e}} T_{5}^{\prime}=T_{4}+\frac{\delta t}{C_{4}} \dot{Q}_{p c}
$$

With the diagram shown in Fig. 2, applying a similar method to each node, we can pose the following system of equations:

$$
[M]\left[T_{i}^{\prime}\right]=\left[T_{i}\right]+\frac{\partial \tau}{C_{i}}\left[\dot{Q}_{i}\right]
$$

In which $[\mathrm{M}]$ is the matrix representative of the system and gives us the relation between the nodes; the vector $\left[T_{i}{ }^{\prime}\right]$ represents the node temperatures in the next iteration and the vector $\left[T_{i}\right]$ represents the node temperatures in the current iteration; the vector $[\dot{Q}]$ represents the internal generation of heat flux in each of the nodes.

In the node corresponding with the water, the term $\dot{Q}_{p c}$ represents the heat flux absorbed for the phase change process. When both solid and liquid phases coexist and until the phase change is over $\left(\mathrm{T}_{4}=\mathrm{T}_{4}{ }^{\prime}\right)$, this condition is given by the expression:

$$
\frac{T_{4}^{\prime}-T_{3}^{\prime}}{R_{v-w}}+\frac{T_{4}^{\prime}-T_{5}^{\prime}}{R_{w-i c e}}=\dot{Q}_{p c}
$$


The model also incorporates the equations of the thermoelectric phenomena, which are the heat fluxes due to the Peltier effect, equations (7) and (8), and Joule effect equation (9), assuming no magnetic field.

$$
\begin{aligned}
& \dot{Q}_{h p}=-N 2 \alpha_{h p} I T_{h p}+I^{2} R_{c} \\
& \dot{Q}_{c p}=N 2 \alpha_{c p} I T_{c p}+I^{2} R_{c} \\
& \dot{Q}_{J}=I^{2} R_{0}
\end{aligned}
$$

\subsection{Thermal resistances and capacities calculation.}

The model needs, as inputs, the values of the thermal capacities of each node and the thermal resistances between the nodes. The nodes represent the components of the icemaker or part of the components.

In order to describe the transient thermal behaviour of the system the thermal capacity of each of the nodes is required. These are described by the following expression:

$$
C=V \rho c_{p}
$$

The thermal resistance and capacity of each Peltier module, as well as the thermal resistance between the room and the freezer compartment, the thermal resistance between the room and the refrigerator compartment, and their thermal capacities are studied as described in the reference [7].

The thermal resistance of the contact between the cold side of Peltier module and the finger, and the thermal resistance of the contact between the dissipater and the hot side of the Peltier module have been obtained taking into account the research of Ritzer and Lau [11]. 
The calculation of the thermal resistance of the dissipater, (Fig. 1), was made using a 3D computational model, using a fluid mechanics computational program (FLUENT). This study analyses the distribution of temperatures in the dissipater, in order to obtain the information necessary to carry out an appropriate design of the components of the prototype. As a result of this study, we determined the thermal resistance of the dissipater, which was added to the computational model described here.

In order to study the influence of the dissipater the following configurations were investigated:

- Configuration 1: without fins and with a fan

- Configuration 2: with fins and with a fan

- Configuration 3: with fins and with two fans

Fig. 3 shows the temperature distribution for configuration 1. With the different configurations we tried to diminish the temperature difference between the hot side of the Peltier module and the air of the freezer compartment.

Fig. 3: Dissipater temperature distribution for configuration 1.

The thermal resistance between the dissipater and the freezer compartment was obtained using FLUENT for each of the three configurations of the dissipater. These values are given in Table 1.

\begin{tabular}{|c|c|c|}
\hline Configuration & Technical characteristics & Thermal resistance [K/W] \\
\hline 1 & Dissipater without fins and with a fan & 0.82 \\
\hline 2 & Dissipater with fins and with a fan & 0.30 \\
\hline 3 & Dissipater without fins and with two fans & 0.24 \\
\hline
\end{tabular}

Table 1: Dissipater thermal resistance

With the 3D computational model (FLUENT) the thermal resistance between the part of the fingers in contact with the Peltier module and the ice cubes was investigated. 
The "fingers" consist of a flat plate and some cylindrical fingers, as is shown in Fig. 1. The temperature distribution lets us study the areas that need improvements in the insulator; as can be seen in Fig. 4.

Fig. 4: Distribution temperature in the fingers.

The thermal resistance between the ice and the liquid water of the vessel is composed of two terms. The first corresponds to the conduction of heat through the ice and the second is the natural convection between the liquid water and the surface of the ice. These terms vary with the thickness of the ice. This thermal resistance is defined as:

$$
R_{w-i c e}=\left[\frac{1}{4 \cdot 2 \cdot \pi \cdot L_{f}}\left(\frac{\log \left(\left(r_{f}+e_{i c e}\right) / r_{f}\right)}{k_{i c e}}+\frac{1}{\left(r_{f}+e_{i c e}\right) h_{w-i c e}}\right)\right]
$$

The thermal resistance associated with the phase change was the most complex terms to calculate, because it depends on the geometry of the cold body in contact with the fluid, and the type of fluid. A reference to these kinds of problems, known as boundary value problems, is given in reference [12].

In the case of the thermoelectric ice-maker, by using the data we have determined an average value for the heat transfer coefficient due to the phase change and natural convection between ice and liquid water. The surface of the ice cube increases as the mass of the ice cube increases, therefore the thermal resistance between the node that represents the solid phase and the node that represents the liquid phase is a function of time.

The flat plate and cylinder fingers are in contact with the ice and also have an area in contact with the air contained in the refrigerator compartment, and another area which is in contact with the insulator, as can be seen in Fig. 1. Their thermal resistances are expressed in the following: 


$$
\begin{aligned}
& R_{f-r e f}=\left[\frac{1}{4 \cdot 2 \cdot \pi \cdot L_{f}}\left(\frac{1}{r_{f} h_{r e f-f}}\right)\right] \\
& R_{i n-f}=\frac{e_{i n-f}}{k_{i n} A_{i n-f}}
\end{aligned}
$$

The thermal resistance between the vessel and the water, expression (14), is due to the natural convection between the interior of the vessel walls which is a rectangular cavity open at the top, and the water. The heat transfer coefficient of natural convection is calculated by an experimental adjustment of the test results.

$$
R_{v-w}=\frac{1}{h_{v-w} \cdot A_{v-w}}
$$

The thermal resistance between the vessel and the refrigerator compartment has two terms. The first is heat conduction through the vessel material and the second is the natural convection between the air of the refrigerator compartment and the exterior of the vessel:

$$
R_{r e f-v}=\frac{e_{v}}{k_{v} \cdot A_{r e f-v}}+\frac{1}{h_{r e f-v} \cdot A_{r e f-v}}
$$

The heat transfer coefficients for natural convection between the refrigerator compartment air and the vessel $\mathrm{h}_{\text {ref-v }}$ and between the refrigerator compartment air and the fingers $h_{\text {ref-f }}$ were calculated using the same methodology as can be seen in the reference [13].

The thermal resistance between the refrigerator compartment and the insulator is calculated by expression (16), and to calculate the thermal resistance between the insulator and the dissipater expression (17) is used.

$$
R_{r e f-i n}=\frac{e_{r e f-i n}}{k_{i n} \cdot A_{r e f-i n}}
$$




$$
R_{i n-d}=\frac{e_{i n-d}}{k_{i n} \cdot A_{i n-d}}
$$

\section{Experimental apparatus}

This part of a research project was developed with the assistance BOSCH SIEMENS company. The objective was the development of a thermoelectric ice maker in a vapour compression domestic refrigerator. The application is patented by the BOSCH SIEMENS company, the Patent reference is shown in [14].

The assembly of a prototype thermoelectric ice maker is shown in Fig. 5. The ice maker was placed in the interior of a BOSCH KGP 3933007 refrigerator, and consisted of:

- A methacrylate vessel of $(164 * 50 * 50 \mathrm{~mm})$ with a wall thickness of $2 \mathrm{~mm}$ which contains the water to make the ice cubes.

- The component that makes the ice cubes consists of four aluminium cylinder of $10 \mathrm{~mm}$ diameter and $35 \mathrm{~mm}$ height, the "fingers", joined to a flat aluminium plate that is in contact with the cold side of the Peltier module.

- An aluminium heat dissipater of $\left(423 * 155^{*} 15 \mathrm{~mm}\right)$, which is used to dissipate the heat flux produced by the hot side of the Peltier module. This element connects the hot side of the Peltier module with the freezer compartment.

- Two Marlow DT12-8L Peltier modules, [15].

A photograph of the ice maker assembly in the interior of the domestic fridge and the ice cubes formed can be seen in the Fig. 5 .

Fig. 5: Final assembly photographs of the ice maker prototype. 


\section{Results and discussion}

\subsection{Methodology}

The tests were made in the interior of a climatic chamber in order to control the room temperature and humidity. The results obtained with the prototype were used, to adjust the computational model, and to compare the accuracy of the model with experimental results. The measured input parameters, were:

- Peltier module voltage.

- Temperature settings in the freezer compartment and in the refrigerator compartment.

- Dissipater thermal resistance:

- In function of dissipater type (with or without fins).

- In function of air flow when we change the fan configuration (one or two fans).

- Initial water temperature.

\subsection{Validation of the computational model}

To validate the computational model, we used configuration 1 and the least favourable conditions in the fridge for the production of ice cubes, these conditions correspond with the positions of the thermostats $\left(T_{\text {ref term }}=281 \mathrm{~K}, \mathrm{~T}_{\mathrm{fr}}\right.$ term $\left.=255 \mathrm{~K}\right)$ in which the fridge has the maximum temperatures.

The model solves the ice cube formation process in the transient state with high accuracy, as is illustrated in Fig. 6. Where the test was performed with a Peltier module supply voltage of $3 \mathrm{~V}$, the results show that the experimental temperatures of the 
prototype components have the same tendency as the temperatures simulated by the computational model.

Fig. 6: Experimental and simulated temperatures of the transient state.

Fig. 7 shows the comparison between experimental and simulated temperatures of two components, the finger and dissipater, as a function of the Peltier module supply voltage. The temperatures are average values calculated during the ice cube formation process in a transitory state. As the Peltier voltage is increased the dissipater temperature increases. The finger temperature has its minimum value when the Peltier supply voltage is $3 \mathrm{~V}$ at which point the ice production will be highest.

Fig. 7: Comparison between experimental and simulated temperatures as a function of Peltier voltage.

The model results are very close to the experimental results with deviations in the average temperature of less than $1.5 \mathrm{~K}$, as can be seen in the Fig. 7. The accuracy of the computational model can also be seen in Tables 2 and 3.

\subsection{The influence of the refrigerator compartment and finger temperature on the production of ice cubes.}

The temperatures of the two elements that have most influence on the production of ice are those of the refrigerator compartment and the fingers. In order to determine their influence the test was performed in the most and least favourable conditions and the results compared with the simulated values of the computational model. In this process of comparison we used configuration 1 , (Table 1).

\subsubsection{Test conditions}


Two types of tests were performed, one with the least favourable conditions for ice cube production and the other with the most favourable conditions for ice cube production.

The tests were performed with a room temperature of $298 \mathrm{~K}$, for the same time period.

A) For the least favourable conditions, with $\mathrm{T}_{\text {ref term }}=281 \mathrm{~K}, \mathrm{~T}_{\mathrm{fr} \text { term }}=255 \mathrm{~K}$, and by the maximum ice production corresponded to a Peltier module supply voltage of $2 \mathrm{~V}$. For voltages in excess of $2 \mathrm{~V}$ the ice production decreases, as shown in Table 2. This is due to the fact that when the Peltier module voltage is higher than $2 \mathrm{~V}$, the finger temperature and the refrigerator compartment temperature both increase and consequently the production of ice cubes decreases.

With the values obtained in the test and by using a multiple regression model, we obtain the followings expressions for ice production:

$$
\begin{aligned}
& \dot{m}_{\text {ice }}=95.4308-0.2927 T_{f}-0.0558 T_{\text {ref }}(\text { Model }) \\
& \dot{m}_{\text {ice }}=92.1627-0.2785 T_{f}-0.0567 T_{\text {ref }}(\text { Experimental })
\end{aligned}
$$

\begin{tabular}{|c|c|c|c|c|c|c|c|c|c|}
\hline \multirow{2}{*}{$\mathrm{V}_{\mathrm{p}}(\mathrm{V})$} & \multicolumn{3}{|c|}{$\mathrm{T}_{\mathrm{f}}(\mathrm{K})$} & \multicolumn{3}{c|}{$\mathrm{T}_{\text {ref }}(\mathrm{K})$} & \multicolumn{3}{c|}{$\dot{m}_{\text {ice }}(\mathrm{kg} /$ day $)$} \\
\cline { 2 - 11 } & $\exp$ & Sim & error & $\operatorname{Exp}$ & sim & error & $\exp$ & sim & error \\
\hline 0 & 269,0 & 269,9 & $-0,9$ & 281,3 & 280,7 & 0,7 & 1,00 & 0,75 & 0,25 \\
\hline 1 & 268,5 & 268,2 & 0,4 & 281,1 & 280,5 & 0,6 & 1,68 & 1,26 & 0,42 \\
\hline 2 & 267,0 & 266,7 & 0,2 & 280,1 & 280,8 & $-0,7$ & 1,87 & 1,65 & 0,22 \\
\hline 3 & 266,9 & 265,9 & 1,0 & 280,4 & 280,8 & $-0,4$ & 1,84 & 1,91 & $-0,07$ \\
\hline 4 & 267,6 & 266,5 & 1,1 & 280,9 & 280,9 & 0,0 & 1,64 & 1,78 & $-0,14$ \\
\hline 5 & 268,3 & 266,9 & 1,3 & 281,1 & 281,0 & 0,2 & 1,57 & 1,59 & $-0,02$ \\
\hline
\end{tabular}

Table 2. Experimental and simulated results (less favourable conditions).

The Peltier module voltage in each configuration has an optimum value for maximum ice production, in which the finger temperature is at its minimum, as can be seen in Fig. 7 (configuration 1). 
In the less favourable conditions the ice production in the fridge increases $84 \%$ from the test where the Peltier module supply voltage is zero to the maximum ice production, with a Peltier module supply voltage of $2 \mathrm{~V}$.

B) For the most favourable conditions when, $T_{\text {ref term }}=275 \mathrm{~K}, \mathrm{~T}_{\text {fr term }}=247 \mathrm{~K}$, the daily production rate for ice cubes are given in Table 3.

\begin{tabular}{|c|c|c|c|c|c|c|c|c|c|}
\hline \multirow{2}{*}{$\mathrm{V}_{\mathrm{p}}(\mathrm{V})$} & \multicolumn{3}{|c|}{$\mathrm{T}_{\mathrm{f}}(\mathrm{K})$} & \multicolumn{3}{|c|}{$\mathrm{T}_{\text {ref }}(\mathrm{K})$} & \multicolumn{3}{c|}{$\dot{m}_{\text {ice }}(\mathrm{kg} /$ day $)$} \\
\cline { 2 - 11 } & Exp & Sim & error & $\operatorname{Exp}$ & Sim & error & Exp & Sim & error \\
\hline 0 & 267,8 & 267,3 & 0,5 & 273,9 & 275,3 & $-1,4$ & 1,77 & 1,70 & 0,07 \\
\hline 1 & 265,6 & 265,3 & 0,3 & 274,5 & 274,8 & $-0,3$ & 2,10 & 2,19 & $-0,09$ \\
\hline 2 & 264,9 & 264,4 & 0,5 & 274,8 & 274,4 & 0,3 & 2,28 & 2,48 & $-0,20$ \\
\hline 3 & 264,1 & 263,8 & 0,3 & 274,7 & 274,3 & 0,4 & 2,42 & 2,63 & $-0,21$ \\
\hline 4 & 263,8 & 263,6 & 0,2 & 274,3 & 274,4 & $-0,1$ & 2,75 & 2,68 & 0,07 \\
\hline 5 & 264,5 & 263,8 & 0,7 & 275,1 & 274,4 & 0,7 & 2,59 & 2,63 & $-0,04$ \\
\hline 6 & 265,4 & 264,6 & 0,8 & 275,2 & 274,6 & 0,6 & 2,17 & 2,44 & $-0,27$ \\
\hline
\end{tabular}

Table 3. Experimental and simulated results (Most favourable conditions).

In the most favourable conditions, the ice production in the refrigerator increases 43 $\%$ from the test where the Peltier module supply voltage is zero to the maximum ice production, with a Peltier module supply voltage of $3 \mathrm{~V}$.

In the same way as in case $\mathrm{A}$, the daily ice cube production were obtained:

$$
\begin{aligned}
& \dot{m}_{i c e}=90.5469-0.2463 T_{f}-0.0853 T_{\text {ref }}(\text { Model }) \\
& \dot{m}_{\text {ice }}=91.4118-0.2436 T_{f}-0.0892 T_{\text {ref }}(\text { Experimental })
\end{aligned}
$$

The Peltier module voltage influences both the finger temperature and the refrigerator compartment temperature. The expressions for daily ice production, [equations from (18) to (21)], show that finger temperature has a greater influence on ice production than the temperature of the refrigerator compartment because the coefficient that multiplies the finger temperature is three times greater than the refrigerator compartment temperature coefficient.

When the least and most favourable conditions are compared the ice production rate increases by $47 \%$, with a Peltier module supply voltage of $3 \mathrm{~V}$. 


\subsection{Influence of the thermal resistance of the dissipater on the hot side of the Peltier module on the production of ice cubes.}

In order to study the influence of the heat dissipater thermal resistance on the production of ice cubes three different configurations were investigated. The thermal resistance for each configuration can be seen in Table 1.

Using the test conditions most favourable for ice production: Freezer compartment temperature at $247 \mathrm{~K}$, a refrigerator compartment temperature of $275 \mathrm{~K}$, and the initial water temperature of $275 \mathrm{~K}$.

The simulated and experimental results for the production of ice cubes for configuration 1 (without fins) can be seen in Table 3 . The results for configuration 2 (with fins and one fan) and configuration 3 (with fins and two fans) can be seen in Table 4. The model accuracy is good, because the error in the values for the production of ice cubes between the experimental and simulated values is less than $15 \%$.

\begin{tabular}{|c|c|c|c|c|c|c|}
\hline \multirow{2}{*}{$\mathrm{V}_{\mathrm{p}}(\mathrm{V})$} & \multicolumn{3}{|c|}{$\dot{m}_{\text {ice }}(\mathrm{kg} /$ day) Config. 2 } & \multicolumn{3}{c|}{$\dot{m}_{\text {ice }}(\mathrm{kg} /$ day) Config. 3 } \\
\cline { 2 - 7 } & $\exp$ & $\operatorname{sim}$ & error (\%) & $\exp$ & $\operatorname{sim}$ & error $(\%)$ \\
\hline 0 & 1,84 & 1,88 & $-2,00$ & 2,02 & 2,00 & 0,84 \\
\hline 1 & 2,36 & 2,33 & 1,34 & 2,39 & 2,43 & $-1,66$ \\
\hline 2 & 2,62 & 2,58 & 1,56 & 2,88 & 2,74 & 4,86 \\
\hline 3 & 2,91 & 2,71 & 6,83 & 3,14 & 3,00 & 4,57 \\
\hline 4 & 2,82 & 2,89 & $-2,36$ & 2,94 & 3,11 & $-5,87$ \\
\hline 5 & 2,68 & 2,82 & $-5,29$ & 2,68 & 3,05 & $-13,87$ \\
\hline 6 & 2,48 & 2,65 & $-6,87$ & 2,62 & 2,93 & $-11,80$ \\
\hline
\end{tabular}

Table 4: Ice cube production in function of Peltier module voltage.

The maximum ice production achieved with this prototype is $3.1 \mathrm{~kg} / \mathrm{day}$, with a Peltier module supply voltage of $3 \mathrm{~V}$, with a power consumption of $30 \mathrm{~W}$ (configuration 3) and with a thermoelectric ice maker COP of 0.92. This thermoelectric ice maker COP is defined as: 


$$
C O P=\frac{\dot{Q}_{f}}{\dot{W}_{P}}
$$

This study emphasises the importance of the thermal resistance of the Peltier module's hot side, as is shown in the references [5] and [16]. A decrease in the dissipater thermal resistance from configuration $1\left(\mathrm{R}_{\mathrm{d}}=0.82 \mathrm{~K} / \mathrm{W}\right)$ to configuration 3 $\left(R_{d}=0.24 \mathrm{~K} / \mathrm{W}\right)$ increases the ice production $14 \%$, as is shown in the Tables 3 and 4.

\subsection{The influence of the initial water supply temperature on the production of ice cubes.}

Simulations were performed with operating temperatures of the chiller and freezer compartment of $\mathrm{T}_{\text {ref term }}=275 \mathrm{~K}$ and $\mathrm{T}_{\text {fr term }}=247 \mathrm{~K}$, (configuration 3). Tests were performed with an initial water temperature ranging from $278 \mathrm{~K}$ to $293 \mathrm{~K}$.

During the ice production process, the first stage relates to the cooling of the water until it achieves the phase change temperature and the second stage relates to the phase change process. The higher the initial water temperature, the longer the first stage takes due to the necessity of cooling a larger thermal gap, therefore the ice production is lower as can be seen in Fig. 8 .

The increase in the production of ice cubes from when the Peltier module supply voltage is zero to when it is $3 \mathrm{~V}$ (maximum production) is greater the lower the initial temperature of the water in the vessel. When the $T_{\text {ini }{ }_{w}}=293 \mathrm{~K}$ the increase in the ice production is $0.42 \mathrm{~kg} /$ day and for a $\mathrm{T}_{\text {ini } \mathrm{w}}=278 \mathrm{~K}$ the increase is $0.85 \mathrm{~kg} / \mathrm{day}$, as shown in Fig. 8.

The finger temperature in the transitory state is function of the initial temperature water, therefore the lower this temperature is, the higher the ice production is. 
Fig. 8: Simulation of ice production for different initial water temperatures as a function of the Peltier supply voltage.

\section{Conclusions}

- A computational model that simulates the behaviour of the thermoelectric ice maker and the behaviour of the vapour compression domestic fridge in which is placed has been developed.

- This model predicts the production of ice, heat fluxes, component temperatures, power consumption and thermoelectric ice-maker COP so the optimal Peltier module supply voltage, to obtain the maximum ice production, can be calculated.

- The model has been experimental validated and the results are acceptable with the errors between the experimental and simulated values of temperatures being less than $1.5 \mathrm{~K}$.

- Expressions that link the ice production with finger temperature and refrigerator compartment temperature have been obtained. We have demonstrated that the influence of the finger temperature is greater than that of the refrigerator compartment temperature.

- We have studied the ice production as a function of setting temperature of the refrigerator and freezer compartment, for the following:

a) In the least favourable conditions the ice production increases by $84 \%$, when varying the voltage from $0 \mathrm{~V}$ to $2 \mathrm{~V}$.

b) In the most favourable conditions the ice production increases by $43 \%$, when varying the voltage from $0 \mathrm{~V}$ to $3 \mathrm{~V}$.

c) The ice cube production increases by $47 \%$ from the least to most favourable conditions, for a Peltier module supply voltage of $3 \mathrm{~V}$. 
- The influence of the thermal resistance of the hot side dissipater in the development of thermoelectric ice makers has been demonstrated with simulations and experimental data. The maximum ice production increases by $14 \%$ as a result of using the 3 rd configuration instead of the 1 st one.

- We have simulated the ice cube production as a function of the initial water temperature, and have shown that the lower this temperature is, the higher the ice cube production is and the greater the increase in the ice production is when the Peliter module supply voltage is increased from $0 \mathrm{~V}$ to $3 \mathrm{~V}$. The increase is 0.42 $\mathrm{kg} /$ day for $293 \mathrm{~K}$ and is $0.85 \mathrm{~kg} /$ day for $278 \mathrm{~K}$.

- We have applied the developed computational model to a thermoelectric ice maker placed in a domestic refrigerator. The results were the following: a maximum ice production of $3.1 \mathrm{~kg} / \mathrm{day}$, a power consumption of $30 \mathrm{~W}$, approximately, for a Peltier module supply voltage of $3 \mathrm{~V}$ with a thermoelectric ice maker COP of 0.92 , and a detachment time for the ice cubes of less than 60 seconds.

\section{Bibliography.}

[1] G. Min, D.M. Rowe, Experimental evaluation of prototype thermoelectric domestic-refrigerators. Applied Energy, 83, (2006), p.p. 133-152

[2] J. Chen et al, Comparison of the optimal performance of single and two-stages thermoelectric refrigeration systems. Applied Energy, 73, (2002), p.p. 285-298

[3] D.M. Rowe, CRC Handbook of Thermoelectrics, (1995), pp. 19-25, ISBN 0-8493-0146-7

[4] J.G. Vián, D. Astrain, J. Esarte, and J.J. Águas, Application of the Thermoelectricity on the Development of a Test-Tube Holder and Wine Expositor with Temperatures Control. Proc. 4th European Workshops on Thermoelectrics. 1998, Madrid, Spain, pp. 19-27.

[5] J.G. Vián, M. Domínguez, D. Astrain, , J. Esarte, D. García, and J.J. Aguas "Simulation by Electric Analogy of a Thermoelectric Cheese Dryer". Proc. 5th European Workshops on Thermoelectrics. 1999, Pardubice, Czech Republic, pp. 99-105.

[6] J.G. Vián, D. Astrain and M. Dominguez, Numerical modelling and design of a thermoelectric dehumidifier. Applied Thermal Engineering 22/4 02, (2002), pp. 407-422

[7] D. Astrain, J.G. Vián, and J. Albizua, Computational model for refrigerators based on Peltier effect application. Applied Thermal Engineering 25, (2005), pp. 3149-3162

[8] D.M. Rowe, Modern Thermoelectrics, (1983), pp 8-9 ISBN 0-03-910433-8 
[9] G.S. Nolas, Thermoelectrics Basic Principles and New Materials Developments, (2001), pp. 5-7, ISBN 3-540-41245-X

[10] A.L. London, R.A. Seban, Rate of ice formation, Transaction of the ASME October, (1943), pp. 771-778

[11] T.M. Ritzer, P.G. Lau, Economic Optimization of Heat Sink Design, 13th International Conference on Thermoelectrics, Kansas City, MO, (1994), pp. 77-100

[12] MN. Ozisik Boundary value problems of heat conduction. Scranton, Penn: International Textbook; (1980).

[13] G.V. Parmelee and R.G. Huebscher, Heat transfer by forced convection along a flat flat surface, Heat Piping Air Conditioning 19 (1947) (8), p. 115.

[14] J.G. Vián, D. Astrain, A. Rodríguez, J. Calvillo, S. García. Thermoelectric system to make ice, 2007, 200701914, BOSCH-SIEMENS, Spain. International: (IPC1-7): F28D15/04 European: F28D15/04B; H01L35/30.

[15] www.marlow.com

[16] D. Astrain, J.G. Vián and M. Domínguez, Increase of COP in the thermoelectric refrigeration by the optimization of heat dissipation, Applied Thermal Engineering 23 (17), (2003), pp. $2183-$ 2200 .

Fig. 1: Diagram of the ice maker prototype.

Fig. 2. Diagram of the electric and thermal analogy of the computational model

Fig. 3: Dissipater temperature distribution for configuration 1.

Fig. 4: Distribution temperature in the fingers.

Fig. 5: Final assembly photographs of the ice maker prototype.

Fig. 6: Experimental and simulated temperatures of the transient state.

Fig. 7: Comparison between experimental and simulated temperatures as a function of Peltier voltage.

Fig. 8: Comparison of ice production for different initial water temperatures as a function of the Peltier supply voltage. 


\begin{tabular}{|c|c|c|}
\hline Configuration & Technical characteristics & Thermal resistance [K/W] \\
\hline 1 & Dissipater without fins and with a fan & 0.82 \\
\hline 2 & Dissipater with fins and with a fan & 0.30 \\
\hline 3 & Dissipater without fins and with two fans & 0.24 \\
\hline
\end{tabular}

Table 1: Dissipater thermal resistance

\begin{tabular}{|c|c|c|c|c|c|c|c|c|c|}
\hline \multirow{2}{*}{$\mathrm{V}_{\mathrm{p}}(\mathrm{V})$} & \multicolumn{4}{|c|}{$\mathrm{T}_{\mathrm{f}}(\mathrm{K})$} & \multicolumn{3}{|c|}{$\mathrm{T}_{\text {ref }}(\mathrm{K})$} & \multicolumn{3}{|c|}{$\dot{m}_{\text {ice }}(\mathrm{kg} /$ day $)$} \\
\cline { 2 - 11 } & $\exp$ & Sim & error & $\operatorname{Exp}$ & $\operatorname{sim}$ & error & $\exp$ & sim & error \\
\hline 0 & 269,0 & 269,9 & $-0,9$ & 281,3 & 280,7 & 0,7 & 1,00 & 0,75 & 0,25 \\
\hline 1 & 268,5 & 268,2 & 0,4 & 281,1 & 280,5 & 0,6 & 1,68 & 1,26 & 0,42 \\
\hline 2 & 267,0 & 266,7 & 0,2 & 280,1 & 280,8 & $-0,7$ & 1,87 & 1,65 & 0,22 \\
\hline 3 & 266,9 & 265,9 & 1,0 & 280,4 & 280,8 & $-0,4$ & 1,84 & 1,91 & $-0,07$ \\
\hline 4 & 267,6 & 266,5 & 1,1 & 280,9 & 280,9 & 0,0 & 1,64 & 1,78 & $-0,14$ \\
\hline 5 & 268,3 & 266,9 & 1,3 & 281,1 & 281,0 & 0,2 & 1,57 & 1,59 & $-0,02$ \\
\hline
\end{tabular}

Table 2. Experimental and simulated results (less favourable conditions).

\begin{tabular}{|c|c|c|c|c|c|c|c|c|c|}
\hline \multirow{2}{*}{$\mathrm{V}_{\mathrm{p}}(\mathrm{V})$} & \multicolumn{4}{|c|}{$\mathrm{T}_{\mathrm{f}}(\mathrm{K})$} & \multicolumn{3}{|c|}{$\mathrm{T}_{\text {ref }}(\mathrm{K})$} & \multicolumn{3}{c|}{$\dot{m}_{\text {ice }}(\mathrm{kg} /$ day $)$} \\
\cline { 2 - 11 } & $\operatorname{Exp}$ & Sim & error & $\operatorname{Exp}$ & $\operatorname{Sim}$ & error & $\operatorname{Exp}$ & Sim & error \\
\hline 0 & 267,8 & 267,3 & 0,5 & 273,9 & 275,3 & $-1,4$ & 1,77 & 1,70 & 0,07 \\
\hline 1 & 265,6 & 265,3 & 0,3 & 274,5 & 274,8 & $-0,3$ & 2,10 & 2,19 & $-0,09$ \\
\hline 2 & 264,9 & 264,4 & 0,5 & 274,8 & 274,4 & 0,3 & 2,28 & 2,48 & $-0,20$ \\
\hline 3 & 264,1 & 263,8 & 0,3 & 274,7 & 274,3 & 0,4 & 2,42 & 2,63 & $-0,21$ \\
\hline 4 & 263,8 & 263,6 & 0,2 & 274,3 & 274,4 & $-0,1$ & 2,75 & 2,68 & 0,07 \\
\hline 5 & 264,5 & 263,8 & 0,7 & 275,1 & 274,4 & 0,7 & 2,59 & 2,63 & $-0,04$ \\
\hline 6 & 265,4 & 264,6 & 0,8 & 275,2 & 274,6 & 0,6 & 2,17 & 2,44 & $-0,27$ \\
\hline
\end{tabular}

Table 3. Experimental and simulated results (Most favourable conditions).

\begin{tabular}{|c|c|c|c|c|c|c|}
\hline \multirow{2}{*}{$\mathrm{V}_{\mathrm{p}}(\mathrm{V})$} & \multicolumn{3}{|c|}{$\dot{m}_{\text {ice }}(\mathrm{kg} /$ day) Config. 2 } & \multicolumn{3}{c|}{$\dot{m}_{\text {ice }}$ (kg/day) Config. 3 } \\
\cline { 2 - 7 } & $\exp$ & $\operatorname{sim}$ & error (\%) & $\exp$ & $\operatorname{sim}$ & error (\%) \\
\hline 0 & 1,84 & 1,88 & $-2,00$ & 2,02 & 2,00 & 0,84 \\
\hline 1 & 2,36 & 2,33 & 1,34 & 2,39 & 2,43 & $-1,66$ \\
\hline 2 & 2,62 & 2,58 & 1,56 & 2,88 & 2,74 & 4,86 \\
\hline 3 & 2,91 & 2,71 & 6,83 & 3,14 & 3,00 & 4,57 \\
\hline 4 & 2,82 & 2,89 & $-2,36$ & 2,94 & 3,11 & $-5,87$ \\
\hline 5 & 2,68 & 2,82 & $-5,29$ & 2,68 & 3,05 & $-13,87$ \\
\hline 6 & 2,48 & 2,65 & $-6,87$ & 2,62 & 2,93 & $-11,80$ \\
\hline
\end{tabular}

Table 4: Ice cube production in function of Peltier module voltage. 


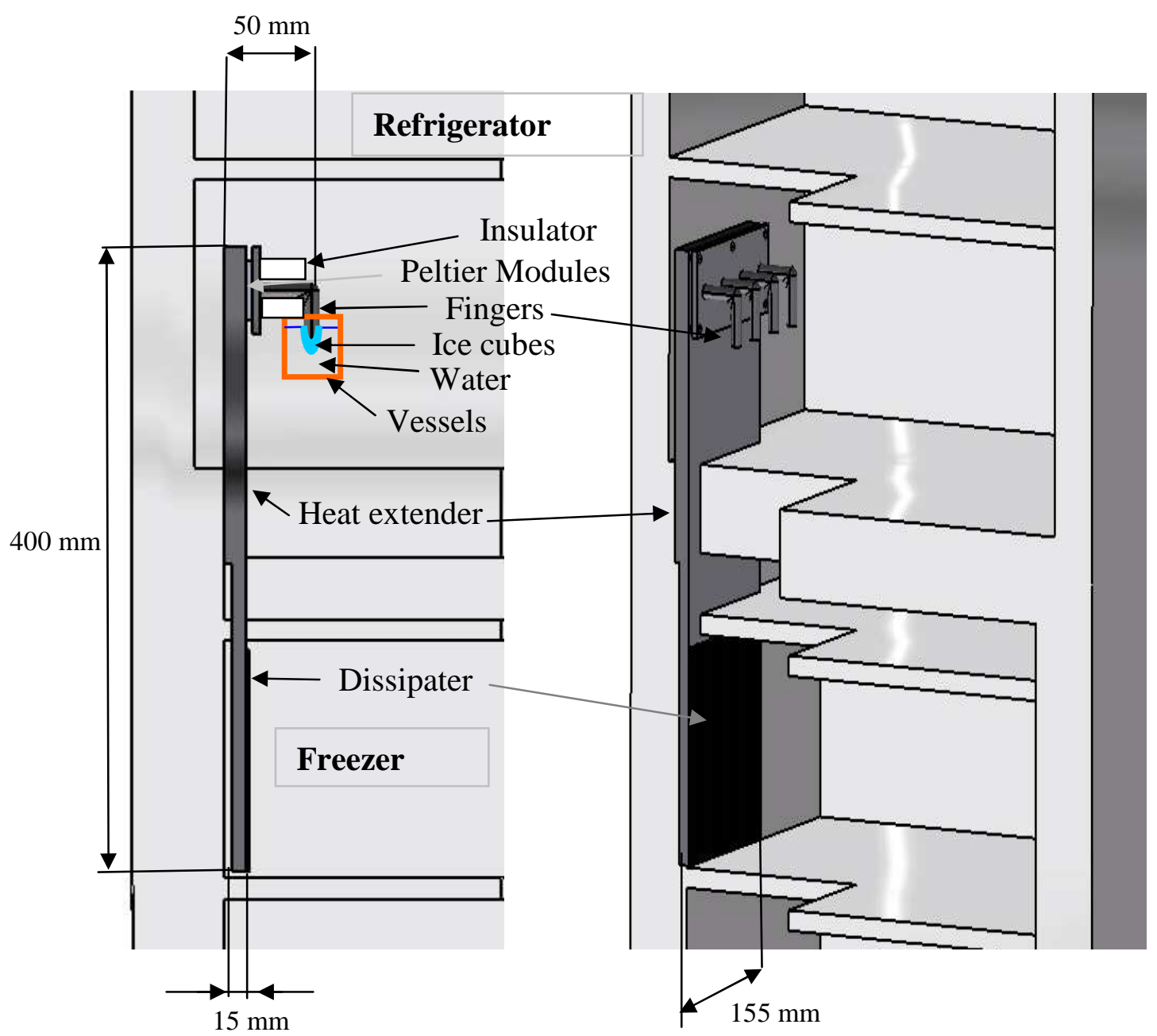

Fig. 1: Diagram of the ice maker prototype.

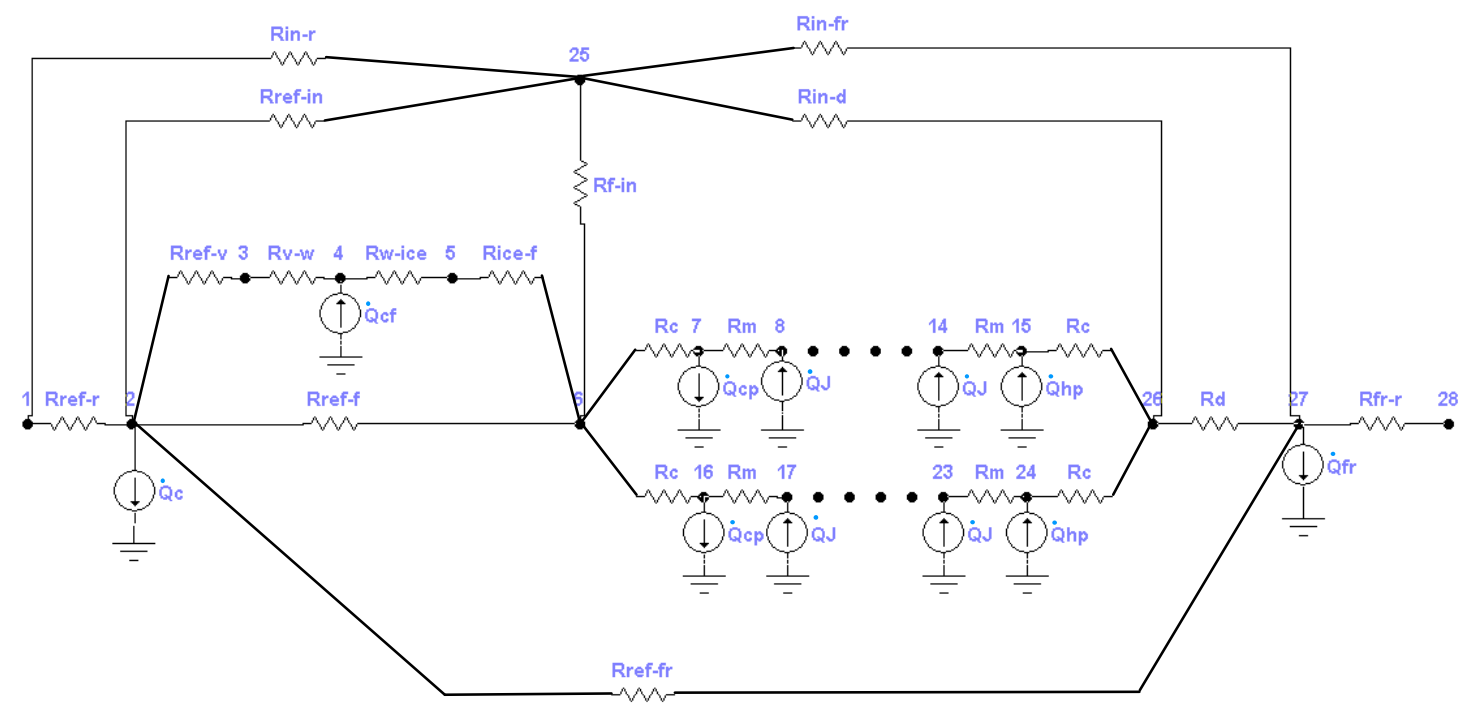

Fig. 2. Diagram of the electric and thermal analogy of the computational model 

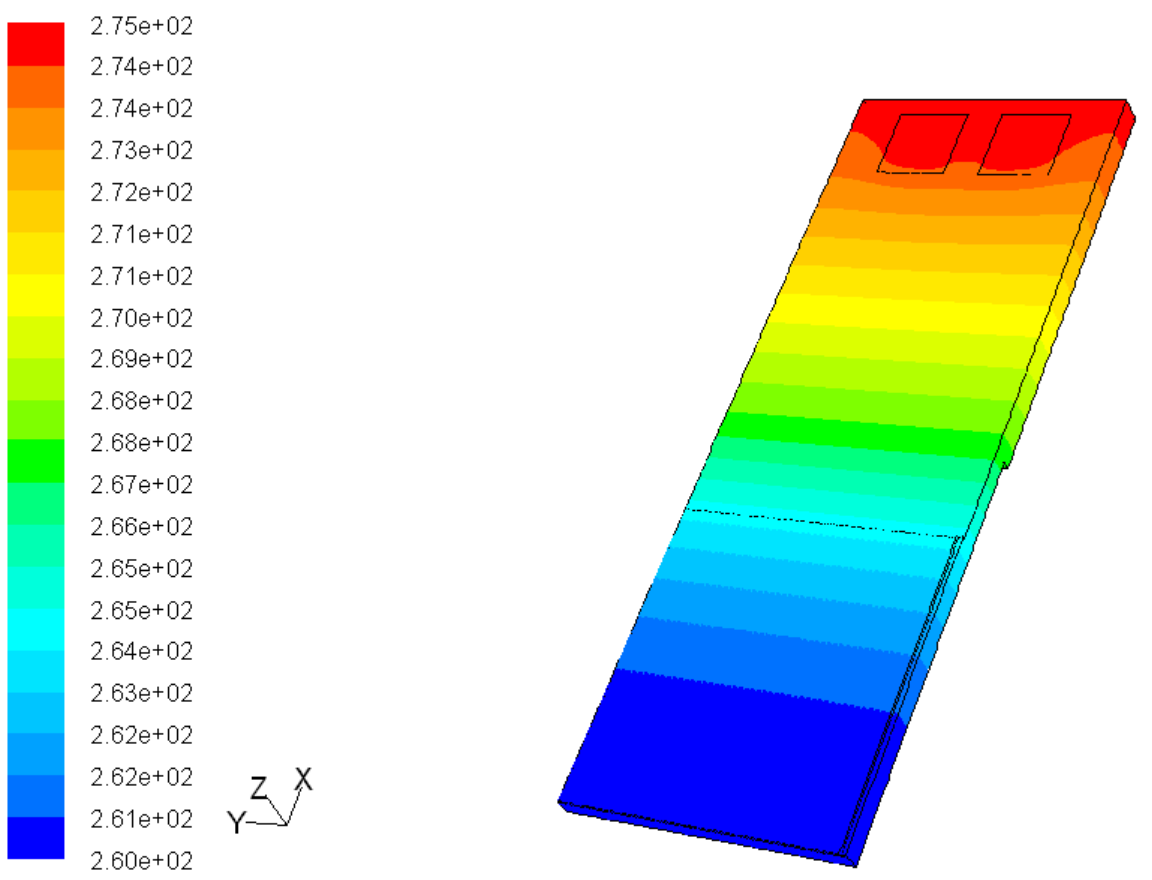

Contours of Static Temperature (k)

Fig. 3: Dissipater temperature distribution for configuration 1.

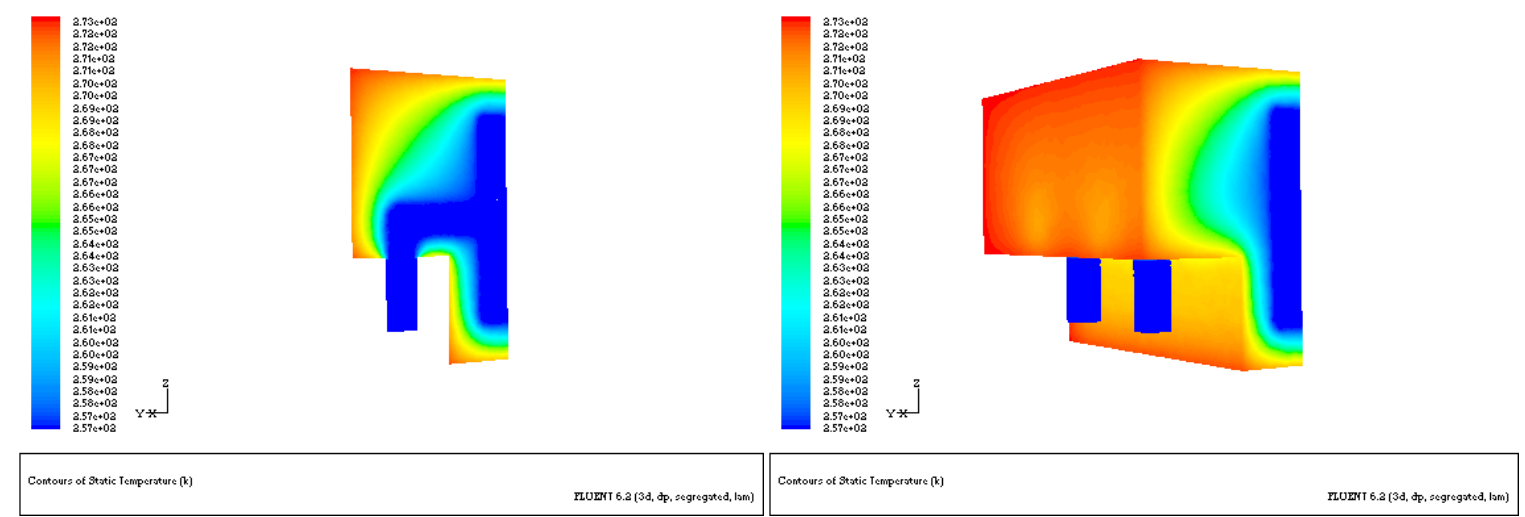

Fig. 4: Distribution temperature in the fingers. 


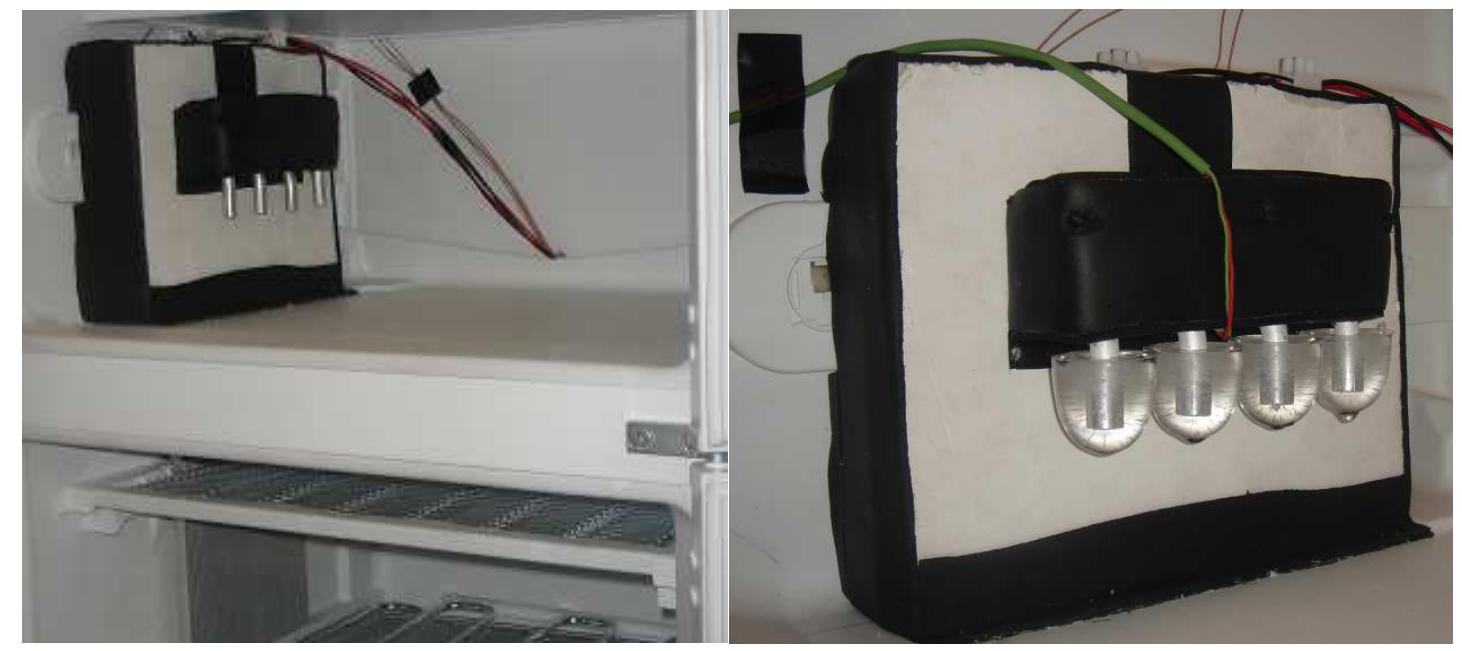

Fig. 5: Final assembly photographs of the ice maker prototype.

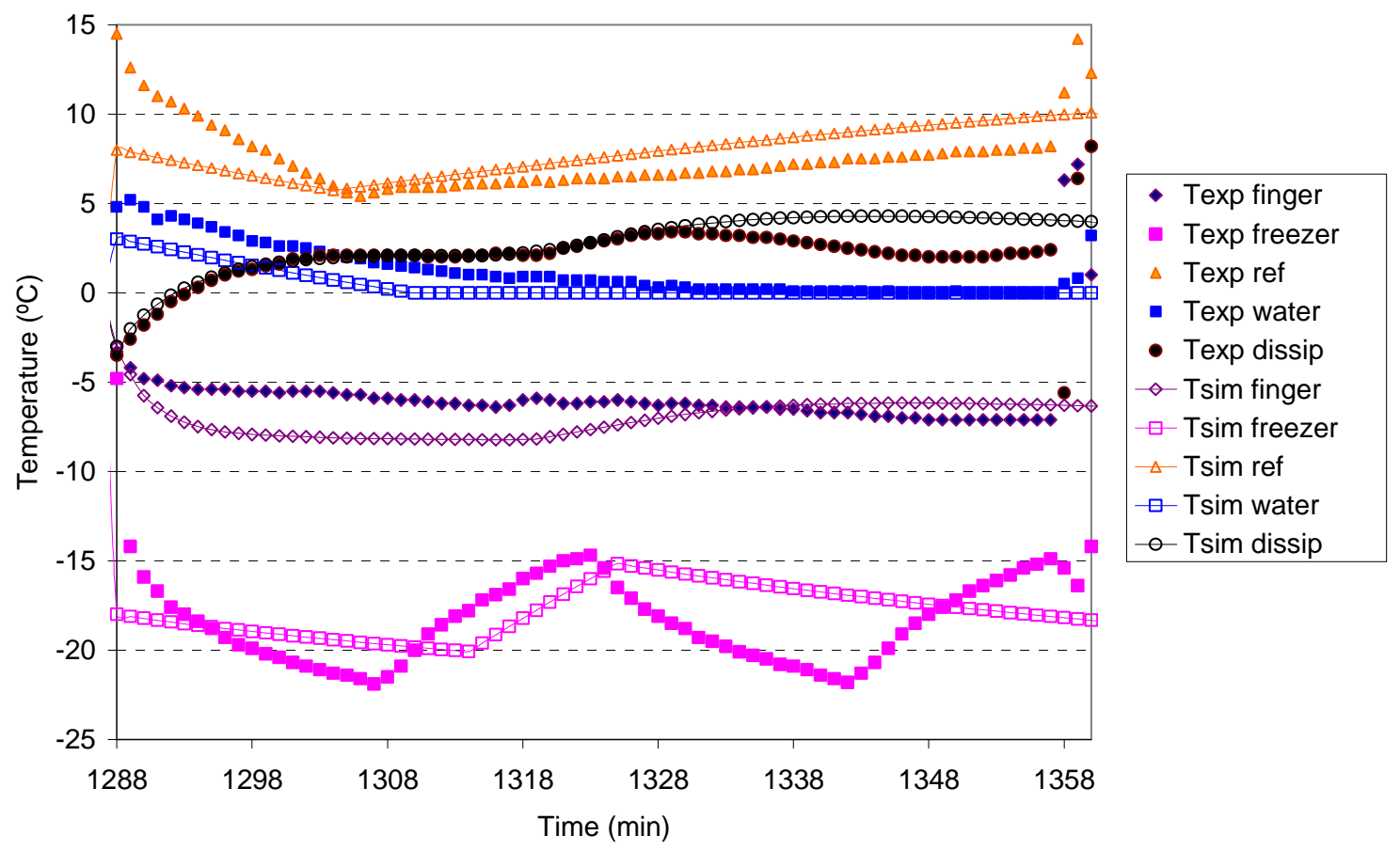

Fig. 6: Experimental and simulated temperatures of the transient state. 


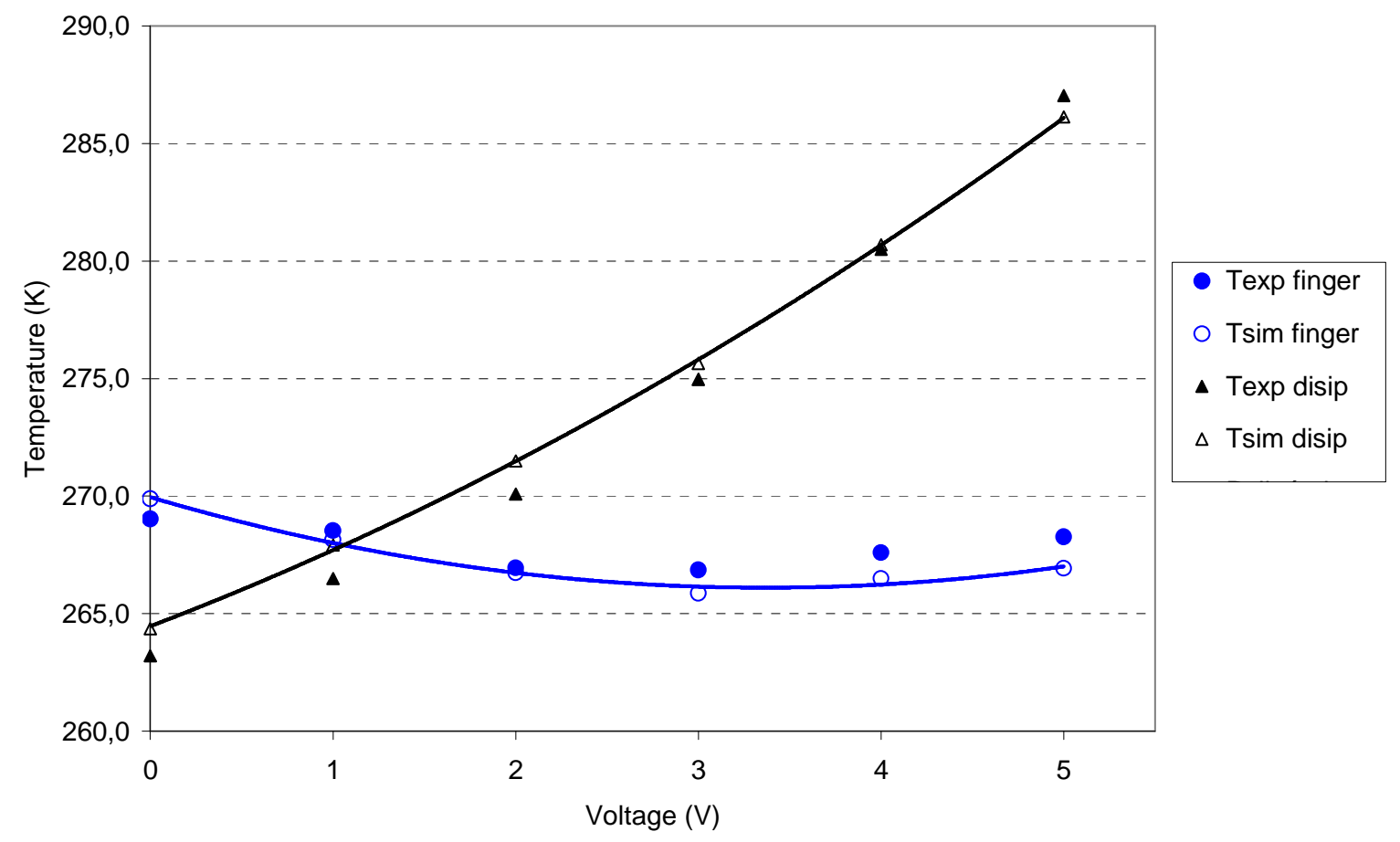

Fig. 7: Comparison between experimental and simulated temperatures as a function of Peltier voltage.

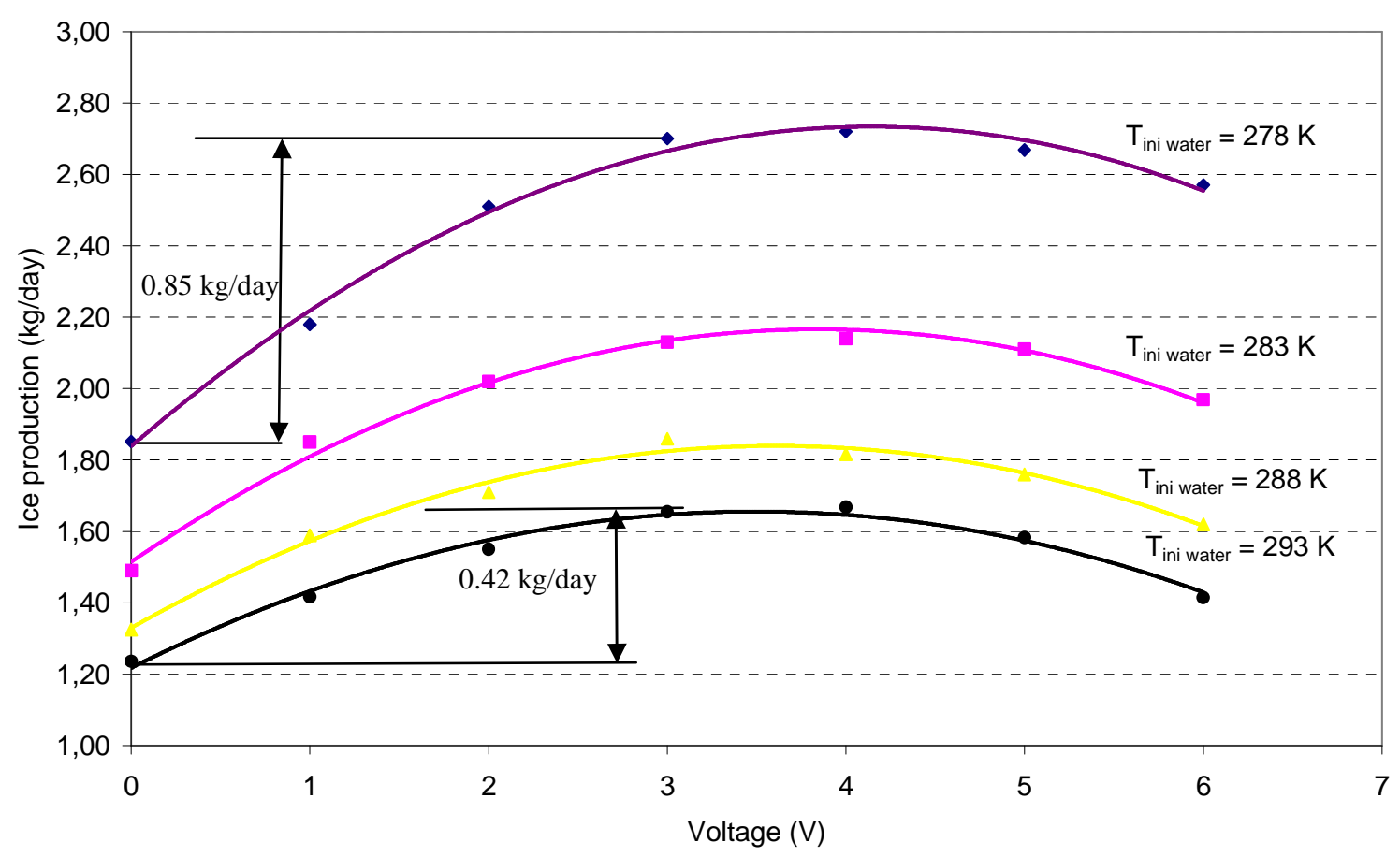

Fig. 8: Simulation of ice production for different initial water temperatures as a function of the Peltier supply voltage. 